\title{
Conversando sobre Guarda Compartilhada e Alienação Parental: Olhares Jurídicos e Psicológicos em um Projeto de Extensão Acadêmica
}

\author{
Dialogue on Joint Custody and Parental Alienation: Legal and Psychological Perspectives \\ in a Project of Academic Extension
}

Conversando sobre Guarda Compartida y Alienación Parental: Miradas Juridicas y Psicológicas en un Proyecto de Extensión Académica

\section{Maicon Roger Gomes Pires}

Graduado em Psicologia. Instituto Luterano de Ensino Superior - ULBRA, Porto Velho, Rondônia, Brasil

E-mail: m.rogergomes@gmail.com

\section{Ágata Cristiam Tavares Barbosa}

Graduada em Psicologia. Instituto Luterano de Ensino Superior - ULBRA, Porto Velho, Rondônia, Brasil

E-mail: cristiam.agata@gmail.com

\section{Ssamandra Machado Razzéra}

Graduanda em Psicologia. Instituto Luterano de Ensino Superior - ULBRA, Porto Velho, Rondônia, Brasil

E-mail: ssamandrazzera@gmail.com

\section{Thayse Alves da Silva}

Graduanda em Psicologia. Instituto Luterano de Ensino Superior - ULBRA, Porto Velho, Rondônia, Brasil

E-mail: oitastas@gmail.com

\section{Marineta Souza de Almeida}

Graduanda em Direito. Instituto Luterano de Ensino Superior - ULBRA, Porto Velho, Rondônia, Brasil

E-mail: marieh.almeida04@gmail.com

\section{Zeno Germano de Souza Neto}

Professor de Psicologia do Instituto Luterano de Ensino Superior - ULBRA, Porto Velho, Rondônia, Brasil

E-mail: zeno.neto@ulbra.edu.br

\section{Resumo}

O seguinte trabalho é o relato de experiência de um projeto de extensão com alunos dos cursos de Psicologia e Direito do Instituto Luterano de Ensino Superior ULBRA, feito em seis escolas públicas estaduais de Porto Velho, Rondônia. O projeto teve o objetivo de realizar grupos de encontro e palestras envolvendo pais, alunos e professores, no intento de divulgar e refletir sobre os conceitos de guarda compartilhada em seus efeitos positivos para a criança e alienação parental (AP), enfatizando os efeitos negativos que tal fenômeno pode causar. Foi alcançado o total de 417 pessoas, em maioria alunos do ensino médio. O referido trabalho ainda está abarcado em referencial teórico jurídico e psicológico, com escopo de ponderar sobre as principais características e efeitos que venham a acarretar na vida dos atores envolvidos. Os resultados relatados aqui apontam o desconhecimento das pessoas e o interesse em saber mais sobre os fenômenos da guarda compartilhada e da AP.

Palavras-chave: guarda compartilhada, alienação parental, escolas públicas. 


\section{Abstract}

This paper is the experience report of an extension program that students from the majors of Psychology and Law at the Lutheran Institute of Higher Learning ULBRA carried out in six state public schools in Porto Velho, Rondonia, Brazil. The project aimed at organizing groups for meetings and lectures involving parents, students and teachers in order to create awareness and to reflect upon the concepts of joint custody in its positive effects for children and of parental alienation highlighting its negative effects. 417 people were involved in this project, mostly students from high school. The project is supported by legal and psychology academic literature and it intends to debate the main characteristics and effects that influence the people involved. The results reported here point out to the unawareness of people in general and the interest for knowing more on joint custody and parental alienation.

Keywords: joint custody, parental alienation, public schools.

\section{Resumen}

El siguiente trabajo es el relato de experiencia de un proyecto de extensión con alumnos de los cursos de psicología y abogacía del Instituto Luterano de Enseñanza Superior ULBRA, realizado en seis escuelas públicas estaduales de Porto Velho, Rondonia, Brasil. El proyecto tuvo el objetivo de realizar grupos de encuentro y charlas involucrando a padres, alumnos y profesores, en el intento de divulgar y reflexionar sobre los conceptos de guarda compartida, en sus efectos positivos para el niño, y alienación parental, destacando los efectos negativos que ese fenómeno puede causar. Fue alcanzado un total de 417 personas, en su mayoría alumnos de nivel secundario. Este trabajo también cuenta con amplio referencial teórico jurídico y psicológico, pretendiendo ponderar sobre las principales características y efectos que estos fenómenos puedan traer a la vida de las personas involucradas. Los resultados aquí relatados apuntan para el desconocimiento de las personas y el interés en saber más sobre los fenómenos de la guarda compartida y de la alienación parental.

Palabras claves: guarda compartida, alienación parental, escuelas públicas.

O presente artigo é fruto da experiência de um grupo de alunos dos cursos de Psicologia e Direito do Instituto Luterano de Ensino Superior - ULBRA, e foi desenvolvido ao longo do ano de 2016 em algumas escolas da rede pública estadual da cidade de Porto Velho, capital do Estado de Rondônia. A experiência desenvolvida tratou de diálogos, em formato de palestras e reuniões, sobre a guarda compartilhada e a alienação parental envolvendo os aspectos psicológicos e dos direitos com a população escolar dessas instituições, onde foram alunos, pais e professores os participantes.
Os objetivos do projeto previam levar a informação sobre os temas para a comunidade e possibilitar um espaço de reflexão para que as pessoas pudessem se manifestar quanto a suas dúvidas e interesses sobre os fenômenos abordados. Outro aspecto a se configurar como objetivo foi de cunho acadêmico, possibilitando aos alunos a vivência de transmissor de conhecimento, facilitador do processo de comunicação entre as pessoas e também de aprendiz, tanto no que diz respeito ao estudo dos temas como também no sentido de acolher as manifestações dos membros da comunidade e, em sentido amplo, aprender com eles.

\section{Dinâmicas familiares}

Dias (2010) afirma que a alteração do conceito de família, principalmente em relação à importância do sentimento de afeto no âmbito familiar, ocasionou a valoração da filiação afetiva. No entanto, apesar de o afeto ser análogo ao motor que faz um objeto eletrônico funcionar, ele é também um dos principais responsáveis pelo término de uma relação conjugal, levando a criança a ficar desorientada. Além disso, a criança pode se sentir culpada, por acreditar ser o agente provocador do conflito instalado entre os pais. Para a autora, essa crença nada mais é do que um desejo relacionado (Dolto, 1991).

Silva (2011) assegura que, independente da dissolução do casamento dos genitores e da 
configuração da família, o estabelecimento e a manutenção de vínculos afetivos parentais são imprescindíveis para a formação da personalidade da criança. Tais constatações se comprovam com a observação de Zornig: a "História da criança se inicia na história individual de cada um dos pais, atrelado ao desejo de ter um filho, que reatualiza as fantasias de sua própria infância e o tipo de cuidado parental que tiveram". (Zornig, 2010, p. 4).Vista assim, as funções parentais exercidas pelos genitores são fundamentais para o desenvolvimento psíquico da criança: além de estas herdarem a carga genética dos pais, a interação da criança com estas figuras influenciará diretamente na formação de sua personalidade. Sobre a provisão ambiental, Winnicott (2011) considera que é no âmbito familiar que a criança aprende a noção de grupo, e a partir desta relação ela constituirá novas relações, pois "o jogo familiar é um preparo perfeito para a vida" (Winnicott, 2011, p. 135), assim se constituindo em um campo dinâmico.

Seguindo a ideia de um campo dinâmico, de acordo com Zimmerman (2009), uma figura materna suficientemente boa exerce funções imprescindíveis para o desenvolvimento emocional salutar de uma criança, e deve permitir a entrada do pai na vida da criança. É por meio da ingressão da figura paterna que ocorrerá a dessimbiotização entre mãe e filho, e concomitantemente surgirá o triângulo edípico. As funções que a figura materna exerce na vida dos filhos vão desde as necessidades mais elementares, importantes para a sobrevivência da criança, como alimentação, contato físico, cuidados, entre outros, até as mais complexas, como capacidade de holding, que seria uma forma de a mãe acolher a demanda do filho, decodificando-a e devolvendo-a para este.

Quanto à entrada do pai, Lacan (1999) defende que é a partir do Complexo de Édipo que o pai exercerá a sua função. Em decorrência dessa incidência, a criança poderá adquirir capacidade de reconhecimento da existência do outro, partindo assim da transição do narcisismo (eu) ao Édipo (outro). Nesse ponto, as novas configurações familiares trazem, dentre outros aspectos, novos cenários quanto ao papel do pai no arranjo familiar, deixando o lugar de mero provedor e alcançando o exercício do cuidado afetivo anteriormente restrito à mãe.

\section{Alienação parental e Síndrome da Alienação Parental}

Trindade (2014) relaciona a alienação parental com a coparentalidade maligna, que consiste na formação de morte simbólica representada pelo ódio, pois diante da ruptura dos laços matrimoniais muitos genitores geralmente apresentam instabilidade emocional e imaturidade para manejar esta situação. Esse ambiente do conflito é propício para a ocorrência da AP, em que os adultos não hesitam em utilizar os filhos em comum como instrumento de vingança direcionada ao outro.

Para Madaleno (2014), a AP pode surgir no decorrer da disputa judicial pela guarda dos filhos, pois o processo de separação tende a despertar sentimentos de traição, rejeição, abandono e angústia; assim como pode ser fruto do luto não elaborado.
Afirma a autora que a AP égeralmente praticada por quem possui guarda física da criança e passa a utilizá-la como um instrumento para vingança, para atingir o outro genitor. Além do genitor guardião, este ato pode ser praticado por outros membros familiares, como tios, primos, avós da criança. A alienação é um trabalho contínuo, que ocorre muitas vezes de maneira imperceptível.

Os fatores que possibilitam a identificação da AP segundo Madaleno (2014) incluem realizar campanha de desqualificação da imagem do genitor não guardião; limitar ou impedir o contato do filho com o pai, utilizar chantagem emocional, ameaçar abandono ou suicídio caso o filho seja desleal para com o alienador, alterar endereços ou mudar de cidade sem o conhecimento e o consentimento do outro genitor, provocar o distanciamento 
emocional e físico da criança do outro genitor, implantar falsas memórias de abuso sexual na criança, dentre outros. É importante salientar que é a partir desses fatores que a AP é implantada.

Quando a conduta alienadora é estabelecida, é possível identificar na criança um conjunto de sintomas manifestados por sentimentos de ódio, raiva, desprezo pelo outro genitor. Portanto, "Quando a AP já está estabelecida, a criança adere à campanha de difamação, assumindo o papel de ofender o genitor alienado, com injúrias, calúnia, agressões, rompimento dos laços, etc." (Madaleno, 2014, p. 43).

É possível também identificar algumas características gerais na conduta alienadora. Em termos explicitados por Trindade (2014), o genitor alienador mantém uma relação simbiótica com seu filho, e o genitor alienado é visto como um intruso nesta relação, devendo ser removido a qualquer custo. Portanto, a vítima infantil é percebida como um objeto que garantirá a sua continuidade; por isso, a utiliza para atingir o outro alienado. Além disso, segundo o autor, realçam-se na conduta do alienador ausência de consciência moral, atitudes marcadas pela ausência de qualquer empatia para com o outro, e não consegue distinguir a diferença entre a verdade e a mentira. Com esta forma de agir, monitora o tempo que o filho dispensa ao outro genitor e também os sentimentos para com este. As frustrações são manifestadas de modo pungente e mútuo, impossibilitando qualquer defesa do filho. Estes acabam por ver recorrentemente, com olhar amedrontado, a peleja por sua guarda e forçadamente vivencia o inevitável afastamento de entes queridos como avós, tios, primos, etc. (Neta, 2012).

Então, é preciso ter um olhar abrangente sobre todo o contexto da criança a fim de perceber a AP, inclusive porque esta dinâmica acaba por acontecer de modo inconsciente, é "uma moléstia e em muitas situações o alienador não tem consciência plena do mal causado. Sua intenção é mais do que denegrir, destruir o outro genitor perante os filhos" (Venosa, 2013, p. 333). Assim como a influência positiva da educação que a relação dos pais um com o outro tende a beneficiar a criança, o inverso também resulta em malefícios incomensuráveis. Em meio à contradição de sentimentos, é produzida a deterioração dos vínculos que, caso persista por muito tempo, implantará um processo de cronificação irreversível, "fazendo da morte simbólica da separação, uma morte real do sujeito" (Trindade, 2014, p. 329).

De modo sucinto, a Síndrome de Alienação Parental não é ato em si, mas as consequências sintomáticas que a AP pode causar; e pode se apresentar enquanto os pais ainda estão casados - apesar de os casos mais comuns serem os que ocorrem com a separação dos pais, em que o cônjuge que detém até então a guarda da criança, por não aceitar o término do relacionamento, incute no menor um sentimento de mágoa, raiva, medo, afastando assim o filho do genitor.

Sobre o tema Carvalho (2010) diz o seguinte:

A implantação paulatina e constante na memória do filho, pelo genitor que possui a guarda, de falsas verdades acaba por causar na criança ou adolescente a sensação de que foi abandonado e não é querido pelo outro, causando um transtorno psicológico que o leva a acreditar em tudo que foi dito em desfavor do guardião descontínuo e passa a rejeitá-lo, dificultando as visitas e tornando-se cada vez mais distante até aliená-lo, tornando-se órfão de pai vivo, o que é extremamente prejudicial para ambos. (Carvalho, 2010, p. 66).

Este conjunto de sintomas varia desde a depressão ao abuso de drogas diante da ausência de um ser tão simbólico, e vem sensibilizando profissionais da área do da Saúde e do Direito. O prejuízo sentido por pais prejudicados em conviver com seus filhos acabou por ter reflexos na legislação.

A lei que trata da AP é a Lei 12.318/10, com o fim de inibir pais e familiares inconsequentes, por causarem prejuízos aos filhos vítimas de manipulações por parte de um dos cônjuges, cuja finalidade é atingir o outro genitor. Pode-se pensar que esta lei vem como uma tentativa formal de coibir familiares que, movidos por interesses 
pessoais, tentam restringir o convívio correto entre filho e algum ente querido, de modo que passe a vigorar com mais efetividade o direito fundamental dos indivíduos envolvidos, e de limitar autoridades parentais inadequadas para o bom desenvolvimento de seus filhos (Buosi, 2012, p. 83).

\section{Alienação parental segundo a Lei 12.318/2010}

A alienação parental de acordo com a Lei $12.318 / 2010$, artigo $2^{\circ}$, é conceituada como:

\section{A interferência na formação psicológica da criança ou do adolescente promovida ou induzida por um dos genitores, pelos avós ou pelos que tenham a criança ou adolescente sob a sua autoridade, guarda ou vigilância para que repudie genitor ou que cause prejuízo ao estabelecimento ou à manutenção de vínculos com este.}

A Lei 12.318/2010 tem por objetivo dar mais segurança ao juiz que aplicará a guarda compartilhada, e servir de apoio para o genitor que será detentor de tal guarda. Em seu artigo $2^{\circ}$, parágrafo único, estão dispostas as formas exemplificativas de atos alienatórios: I - realizar campanha de desqualificação da conduta do genitor no exercício da paternidade ou maternidade; II dificultar o exercício da autoridade parental; III - dificultar contato de criança ou adolescente com genitor; IV - dificultar o exercício do direito regulamentado de convivência familiar; $\mathrm{V}$ - omitir deliberadamente ao genitor informações pessoais relevantes sobre a criança ou adolescente, inclusive escolares, médicas e alterações de endereço; VI apresentar falsa denúncia contra genitor, contra familiares deste ou contra avós, para obstar ou dificultar a convivência deles com a criança ou adolescente; VII - mudar o domicílio para local distante, sem justificativa, visando a dificultar a convivência da criança ou adolescente com o outro genitor, com familiares deste ou com avós.

Havendo indícios de que foi cometida a AP, o juiz determinará com urgência, desde que seja ouvido o Ministério Público, as medidas necessárias para que seja preservada a integridade psicológica da criança ou do adolescente, incluindo como medida formas de assegurar a convivência do menor com o pai ou a mãe alienado. Se necessário for, o juiz determinará uma perícia psicológica e biopsicossocial: a equipe multidisciplinar designada tem o prazo de noventa dias para apresentar o laudo que, conforme o caso, compreenderá entrevista pessoal com as partes, avaliação da personalidade de todos os envolvidos, exame das formas de manifestação da criança acerca da acusação do genitor, e outras maneiras que comprovarão ou não que o menor está sofrendo AP.

Além de exemplificar formas de como a AP ocorre, a lei traz penalidades, sempre pensando no bem-estar da criança ou do adolescente que sofre com a síndrome. Pode o juiz, cumulativamente ou não, advertir o genitor que aliena estipular multa, determinar a alteração da guarda compartilhada, e nos casos mais graves suspender a autoridade parental a fim de que o menor seja retirado do ambiente tóxico promovido pela AP. É importante mencionar que tais penalidades não visam punir o genitor que aliena, e sim ; têm caráter pedagógico pois visam facilitar o convívio do filho com o parente que sofre esta alienação.

\section{Aspectos legais da guarda compartilhada}

No ordenamento jurídico brasileiro, são aplicados alguns tipos de guarda, como por exemplo a guarda alternada e a unilateral. Contudo, com o advento da Lei $\mathrm{n}^{0}$ 13.058/2014 de 22 de dezembro de 2014 (Lei da Guarda Compartilhada), tornou opção primordial - a não ser que sua aplicação no caso concreto não permita - a adoção da guarda compartilhada quando ocorre o divórcio do casal. $\mathrm{O}$ intuito deste instituto, que está alocado dentro do direito civil, mais precisamente no direito de família, é atender aos direitos da criança, à manutenção da saúde tanto mental quanto sentimental, para um melhor desenvolvimento da personalidade que talvez o abandono ou a presença conflituosa causada pela separação dos genitores poderiam 
causar, mantendo os vínculos afetivos que a convivência familiar proporcionaria naturalmente.

A guarda compartilhada confere a participação igualitária dos pais nas atividades do dia-a-dia, como assevera Venosa (2013, p. 185): “A ideia é fazer com que pais separados compartilhem da educação, convivência e evolução dos filhos em conjunto. Em essência, essa atribuição reflete o compromisso dos pais de manter dois lares para seus filhos e cooperar de forma conjunta em todas as decisões". Ainda nesta vertente, devemos observar alguns dispositivos legais que reiteram o pensamento de valorização dos interesses da criança em detrimento dos interesses dos ex-cônjuges. Por exemplo, o artigo 27 da Lei $n^{\circ}$ 6.515/77, de 26 de dezembro de 1977, dispõe que pai e mãe são os titulares dos encargos parentais, persistindo mesmo após o divórcio, ou quando qualquer dos pais contrair novo casamento. Como também o artigo 1.634 do Código Civil preleciona que a ambos os pais compete o exercício pleno do poder familiar. $\mathrm{Na}$ Constituição Federal de 1988, pode-se citar o artigo 229, que aduz o dever de assistência, criação e educação dos filhos menores pelos pais.

Por vezes, os genitores resistem em aderir por vontade própria a guarda compartilhada; contudo, esta relação propõe um ambiente mais harmonioso, podendo transparecer um sentimento de cooperação entre os pais, levando o filho a ter a menor percepção possível de problema. Nesse sentido, não se pode deixar de citar Berenice Dias (2008, p. 28), em cuja obra se encontra a discussão sobre a guarda compartilhada:

A dissolução dos vínculos afetivos não leva à cisão nem quanto aos direitos nem quanto aos deveres com relação aos filhos. O rompimento da vida conjugal dos genitores não deve comprometer a continuidade dos vínculos parentais, pois o exercício do poder familiar em nada é afetado pela separação. É necessário manter os laços de afetividade, minorando os efeitos que a separação acarreta nos filhos.

Outro ponto positivo da guarda compartilhada é a diminuição da possibilidade de haver AP (Lei n ${ }^{\circ}$
12.318/10, de 26 de agosto de 2010) por um dos genitores, que na guarda alternada ou unilateral surge com mais frequência. Por fim, para que haja a perfeita relação na guarda compartilhada, é premissa o trabalho síncrono entre Estado, investido na figura de juízes, conselheiros tutelares e a família, para que possam compreender o principal bem em voga, qual seja o bem-estar da criança, pois é no seio familiar que ocorrem o desenvolvimento da personalidade, a construção do caráter e da educação; e, assim, a quebra da relação conjugal não será empecilho nem atraso para a formação psicológica do filho.

\section{Guarda compartilhada: aspectos psicológicos}

É importante destacar que historicamente a guarda ou o pátrio poder sobre os filhos eram de responsabilidade do pai, enquanto a figura feminina, a mãe, se submetia às suas determinações. Essa concepção considerava a mulher relativamente incapaz para exercer os atos de uma vida civil, dentre os quais estava o fato de não conseguir prover ou ter responsabilidade sobre os filhos. A partir da Revolução Industrial, o papel da mulher será considerado indispensável para a produção e economia, o que permitirá sua inserção cada vez maior no mercado de trabalho e uma melhor divisão das tarefas de educação dos filhos e manutenção do lar. Essa concepção irá impactar também no interior das famílias, até o momento em que, em meados do século passado, a mãe se tornaria a maior responsável de fato pela educação, pelo desenvolvimento, pela condução e orientação dos filhos (Neto\&Fiuza, 2015).

Nos casos de divórcio, costumava prevalecer a guarda unilateral da mãe. Nesse processo unilateral, a criança crescia tendo como referência somente um dos genitores, na maioria das vezes a mãe, que educava, enquanto o pai ficava praticamente ausente dessa criação. Com o divórcio dos pais, os laços entre o pai e os filhos não eram reforçados; se construía a imagem do pai que era um amigo que nos finais de semana buscava o filho para passear, o que retirava deste a responsabilidade na formação da criança. Foi 
para enfrentar essa questão que se instituiu a guarda compartilhada.

Silveira (2014), ao discorrer sobre o conceito de guarda, afirma que a guarda compartilhada busca manter o vínculo entre pais e filhos depois que ocorre a separação do casal. Assim, é preciso ter como prioridade sempre o bem-estar dos filhos, seja por parte dos pais ou da autoridade judicial. O contato de afeto da criança com seus pais fortalecerá um processo de introjeção por elas das imagens parentais; é por meio delas que a criança entenderá e delimitará o papel de cada genitor, estabelecendo vínculos afetivos, que farão parte de sua estrutura psicológica.
A criança não deve perder o contato com um de seus genitores pois, mesmo com o casal separado, é importante para a estruturação de sua personalidade quando adulto, permitindo à criança saber responder a eventos adversos, tais como rejeições, separações e perdas. A separação dos genitores em meio a graves conflitos pode influenciar diretamente na estrutura psicológica das crianças, podendo afetar de forma negativa o desenvolvimento psíquico delas. No contexto exposto, a guarda compartilhada propõe minimizar o sofrimento e seus reflexos psicológicos, como o desenvolvimento de transtornos de personalidade.

\section{A metodologia de execução do projeto.}

Durante o ano de 2016, o projeto de extensão acadêmica "Conversando sobre guarda compartilhada e AP: olhares jurídicos e psicológicos" foi apresentado ao Instituto Luterano de Ensino Superior/ULBRA em Porto Velho, por meio do curso de Psicologia. Após aprovação da faculdade e definição dos alunos voluntários, foram escolhidas aleatoriamente seis escolas da rede pública estadual na cidade de Porto Velho, capital de Rondônia, nomeadas neste artigo com letras alfabéticas. O objetivo do projeto foi informar a comunidade sobre a guarda compartilhada e a AP, realizando palestras informativas com abertura para o diálogo entre alunos de Ensino Médio, pais e professores.

Inicialmente, foram realizados contatos informais com as escolas; e, em um segundo momento, foi apresentado o projeto para conhecimento das direções. Assim que as escolas deram o parecer favorável, foram acertados detalhes quanto a datas e à estrutura dos locais de trabalho dentro das escolas, e iniciadas as atividades. A seguir, é realizado o relato pormenorizado dos trabalhos realizados pelos acadêmicos.

\section{Resultados e Discussões}

Fomos ao Colégio A e aplicamos a primeira palestra para 74 alunos de variados anos do Ensino Médio, com a presença de um professor. Esta palestra teve a participação de muitos alunos com perguntas, desabafos, reflexões. Alguns nos procuraram ao final, outros nos cumprimentaram, e a professora teceu elogios à nossa iniciativa. Seguidamente fizemos outra palestra para 32 alunos também de variados anos escolares. A dinâmica foi a mesma; houve também a presença de uma professora, que também participou nas reflexões sobre os temas.
Os alunos se interessaram pelo tema, relataram casos próprios e tiraram dúvidas. Ao final da atividade, profissionais da escola relataram que o clima dos alunos pós-palestra foi de satisfação pelas informações, que os fizeram pensar sobre um tema tão importante. Sem exceção, os profissionais da escola nos recepcionaram bem, e saímos de lá bastante satisfeitos com mais uma experiência enriquecedora.

Na escola B, a direção nos deu a disponibilidade de vários horários vagos devido à ausência de um professor. Aproveitamos a oportunidade desse 
espaço, implantando o projeto com turmas de alunos da $1^{\circ}$ e $2^{\circ}$ anos. No primeiro dia de palestra, nos apresentamos prontos para o encontro com os alunos. Tínhamos um notebook e pen drive, e contamos com a disponibilidade de um data show, que dispensou o uso do nosso computador. O data show e a sala disponibilizada com ar-condicionado são pontos positivos que valem serem ressaltados. Diretor, supervisora, secretárias, professor nos ajudaram a instalar os aparatos materiais,.

Os alunos, como dito antes, em horários vagos foram direcionados à sala onde seriam feitas as palestras. Começamos pela manhã, com uma turma do segundo tempo, 21 alunos; logo em seguida, recebemos outra turma do $1^{\circ}$ ano, 32 alunos, e a palestra se alongou até o intervalo. Após, acolhemos mais uma turma do $1^{\circ}$ ano, 29 alunos, e ministramos mais uma palestra. No segundo dia, chegamos às 8 horas; porém, só conseguimos palestrar para uma turma do $2^{\circ}$ ano, às 10 horas, 30 alunos, pois um professor estava repondo aula no horário vago; todavia, a secretária direcionou uma turma para a sala onde estávamos. Por fim, palestramos para uma turma do $2^{\circ}$ ano, 29 alunos; e em seguida outra turma do $1^{\circ}$ ano, 27 alunos, que tinham dois períodos vagos. No último dia, nos direcionamos ao diretor, agradecemos o espaço, e nos disponibilizamos a manter uma parceria, assim como à supervisora.

Percebemos que os alunos assimilaram e pensaram sobre o assunto onde fomos muito bem recebidos pela equipe em geral da escola. Fomos alocados em uma sala climatizada, que favoreceu o nosso trabalho, e nos disponibilizaram um datashow, que dispensava o uso de notebook, e caixas de som portátil. Os alunos se comportaram bem, interagiram, opinaram, desabafaram, tiraram dúvidas, aconteceu uma boa dinâmica entre nós e eles. Vale salientar alguns pontos negativos para reflexão. A princípio, houve uma aparente indiferença em relação ao projeto por parte da supervisão da escola; no entanto, pensamos que isso se devesse ao acúmulo de tarefas e ao estresse inerente à dinâmica escolar. Houve alguns imprevistos com alguns integrantes do grupo, como atrasos e ausências; porém, tudo conversado e resolvido a fim de garantir a execução do projeto.

$\mathrm{Na}$ Escola C, as palestras foram realizadas em dois momentos, uma pela manhã e outra à tarde. No período na manhã, recebemos em torno de 37 alunos das turmas $2^{\circ}$ e $3^{\circ}$ anos, e no período da tarde recebemos 27 alunos do $1^{\circ}$ ano. A palestra foi em uma sala em que havia monitor, caixa de som, ar central, e espaço amplo para os alunos. Como metodologia, utilizamos slides, figuras ilustrativas, trechos de episódios da telenovela brasileira "Salve Jorge", transmitida pela Rede Globo em 2012; também passamos trechos do documentário "A morte inventada". Iniciamos explicando o que significava a AP; nesse momento, percebemos que, no decorrer das explicações, os alunos tinham muitas especulações invertidas sobre o tema. Com uma linguagem bastante acessível para os alunos, os vídeos facilitaram o entendimento sobre o tema da AP, gerando várias perguntas e declarações pessoais. Falamos sobre o fenômeno da alienação e das consequências na vida do genitor alienado, da própria criança/ adolescente, e sobre as consequências jurídicas para aqueles que a praticam. Em sequência, falamos sobre uma das formas de prevenção, a guarda compartilhada. Seguimos com mesmo intuito de esclarecer sobre as dúvidas que surgissem sobre o tema e de mostrar os benefícios desse método preventivo contra a Síndrome da Alienação Parental.

No decorrer da apresentação, foi possível observar resistência de alguns alunos no início da palestra, quando se falava sobre $\mathrm{AP}$, principalmente no momento em que mostramos o episódio da alienação e o relato das irmãs do documentário. Mas, no decorrer, os alunos interagiram, fazendo perguntas, buscando respostas para questionamentos, e relatando experiências que acreditavam ser um exemplo de AP. Entre as falas dos alunos, o que mais chamou a atenção foi quando nos foi perguntado se poderia ocorrer alienação com os pais ainda casados, e se poderia ser retirada a guarda de ambos os pais para dá-la a um terceiro.

No final da nossa palestra, a psicóloga da escola pediu a palavra para comentar um fato acontecido 
no dia anterior com um aluno e seus pais sobre alienação, para mostrar aos demais que esses casos não são raros ou distantes das nossas realidades. O projeto distribuiu pirulitos com os telefones de órgãos que podem ser acionados, caso estivessem precisando de ajuda.

$\mathrm{Na}$ Escola D, as palestras foram efetuadas no período da tarde. Inicialmente, recebemos os alunos do $1^{\circ}$ ano do ensino médio, e a palestra foi feita na própria sala onde tinham aula. A escola disponibilizou o monitor e o som, constituídos no mesmo aparelho. Tentamos seguir a mesma metodologia da escola anterior, mas desta vez os vídeos não estavam reproduzindo. Juntando as duas palestras, foi alcançado um total de 37 alunos.
Na Escola E, o primeiro dia foi agendado com o objetivo de trabalhar os pais. Porém, não foi possível realizarmos a palestra pois ninguém compareceu. Conversamos com a diretora e a informamos sobre o ocorrido; então, ela pediu desculpas e disse que convocaria os pais para as próximas palestras. O segundo encontro ocorreu conforme o previsto. Contabilizamos o total de 34 pais e responsáveis. O terceiro encontro também ocorreu conforme o planejado. Neste dia, compareceram 55 pais e responsáveis. $\mathrm{Na}$ Escola F, o acertado junto à Direção foi trabalharmos com os professores inicialmente e em um segundo momento com os pais Contabilizamos o total de oito professores na primeira palestra, e 60 pessoas, entre pais e responsáveis dos alunos, na segunda.

\section{Conclusão}

Atingimos 417 pessoas na comunidade por meio das escolas. Notamos, durante as palestras ministradas, o interesse dos alunos e dos pais pela temática, havendo manifestações do público no sentido de já ter passado ou estar passando pela experiência, ou ainda conhecer pessoas que estariam passando pela experiência de guarda partilhada ou relatam terem sofrido os efeitos danosos da AP. Também foi possível fazer orientações para pessoas que tinham dúvidas sobre como proceder principalmente em casos de
AP. Ficou claro que a passagem por essas escolas deixou um efeito positivo, pelo feedback após as palestras: os alunos elogiaram a iniciativa de debater sobre a origem e os meios de identificação dos atos relacionados à $\mathrm{AP}$, e pais e professores pediram que retornássemos, até mesmo com outros temas pertinentes à sociedade como um todo. Tal experiência tornou-se referência para pensar outras atividades a partir da graduação em Psicologia e em Direito.

\section{Referências}

Brasil, Portal da Legislação. (2010).Lei $n^{\circ}$ 12.318, de 26 de agosto de 2010. Dispõe sobre a alienação parental e altera o art. 236 da Lei $n^{\circ}$ 8.069, de 13 de julho de 1990. Recuperado de: <http://www.planalto.gov.br/ccivil_03/_ ato2007-2010/2010/lei/112318.htm>

Buosi, C. C. F. (2012). Alienação parental uma interface do direito e da psicologia. Curitiba: Juruá Editora.

Carvalho, D. M. (2010). Adoção e guarda. Belo Horizonte: Del Rey.

Dias, M. B. (2008). Guarda Compartilhada. Brasília, DF: Revista Jurídica Consulex.

Dias, M. B. (2010). Síndrome da alienação parental: o que é isso? Teresina: Jus Navigand.
Dolto, F. (1991).Quando os pais se separam.(2a edição). Rio de Janeiro: Jorge Zahar.

Lacan, J. (1999).O Seminário livro 5: as formações do inconsciente. Rio de Janeiro: Jorge Zahar.

Neta, M. R. O. Direito de visitação aos netos de pais separados favorecendo os avós. Conteúdo Jurídico, Brasília-DF, Recuperado de: <http://www.conteudojuridico.com. br/?artigos\&ver $=2.37090>$

Neto, P. C. F., \& Fiuza, K. A. (2015). Aspectos Jurídicos e Psicológicos da guarda compartilhada. Revista Jurídica do UNIARAXÁ,19(18), 209-221. Recuperado de <http:// www.uniaraxa.edu.br/ojs/index.php/juridica/article/ viewFile/388/370> 
Silva, D. M. P. (2011).Guarda compartilhada e síndrome da alienação parental: o que é isto? Campinas: Armazém do Ipê.

Silveira, S. F. J. C. (2014). Os reflexos da guarda compartilhada na formação da criança. Recuperado de <http://tmp. mpce.mp.br/esmp/publicacoes/Edital-02-2014/6Sandra-Fatima-Josete-Camargosil-Silveira.pdf>

Trindade, J. (2014).Manual de psicologia jurídica para operadores do direito.( $7^{a}$ edição). Porto Alegre: Casa do Advogado.
Venosa, S. S. (2013). Direito Civil: direito de família.(13 edição). São Paulo: Atlas.

Winnicott, D. W. (2011).Tudo começa em casa. (5 $5^{\mathrm{a}}$ edição). São Paulo: Martins Fontes.

Zornig, S. M. A. J. (2010). Tornar-se pai, tornar-se mãe: o processo de construção da parentalidade. Tempo Psicanalitico, 42(2), 453-470. Recuperado de <http:// pepsic.bvsalud.org/pdf/tpsi/v42n2/v42n2a10.pdf> 